\title{
Deleterious SMARCA4 Gene Mutation
}

National Cancer Institute

\section{Source}

National Cancer Institute. Deleterious SMARCA4 Gene Mutation. NCI Thesaurus. Code C162746.

A change in the nucleotide sequence of the SMARCA4 gene that is associated with increased risk of disease. 